\title{
Wear of Induction Cladded Coating in the Abrasive Mass at Various Speeds and Impact Angles
}

\author{
Goran HEFFER, Ivan SAMARDŽIĆ, Zdravko SCHAUPERL, Ivan VIDAKOVIĆ
}

\begin{abstract}
The wear of induction cladded coating during motion was investigated through the abrasive mass at a speed of 1.0 to $3.0 \mathrm{~m} / \mathrm{s}$ and the impact angle of abrasive particles with a worn surface of $0^{\circ}$ to $90^{\circ}$. Cladding was performed by using Ni-Cr-Si-B-Fe flame spraying powder. Experimental research was carried out by using the Response Surface Method (RSM) and Central Composite Design (CCD). Analysis of variance proved that both motion speed and impact angle had significant impact on the wear of coating, both individually and interactively. Motion speed had the greatest influence, and the interaction of speed and angle had the least influence. The wear rate increased along with the motion speed increase, and the influence of the impact angle depends on the wear speed. At a speed of $1 \mathrm{~m} / \mathrm{s}$, the wear increases along with the increase of angle from $0^{\circ}$ to $45^{\circ}$ and then continues to decrease up to the angle of $90^{\circ}$. At a speed of $2 \mathrm{~m} / \mathrm{s}$, the wear increases along with the angle increase from $0^{\circ}$ to $30^{\circ}$ and then continues to decrease up to the angle of $90^{\circ}$. At a speed of $3 \mathrm{~m} / \mathrm{s}$, the wear increases along with the angle increase from $0^{\circ}$ to $20^{\circ}$ and then decreases as the angle increases up to $90^{\circ}$. Based on the statistical data processing, this research developed the mathematical model of wear in the form of quadratic polynomial that describes the influences of input variables in individual and interactive form.
\end{abstract}

Key words: abrasive mass; flame spraying powder; impact angle; induction cladded coating; motion speed; wear rate

\section{INTRODUCTION}

All working parts of machinery and equipment used in agriculture, mining and construction industry, in brick and cement industry, in land excavation and transportation, in stone processing, pneumatic transport of mineral substances, etc. are exposed to wear of materials by hard abrasive particles. A special form of such wear occurs when the working part is immersed in a mass of free abrasive particles (abrasive mass) and it moves through this mass at a certain speed, whereby the contact/impact of hard particles and the surface occurs at a certain angle in relation to the direction of the working part motion. During such motion, the surface is simultaneously worn by abrasion and erosion, which is described in previous studies as abrasive erosion [1-6] or impact abrasion [7-13]. Experimental researches into such wear were carried out by using some testing methods on equipment that provided as realistic wear conditions as possible. Such equipment refers to the impeller-tumbler wear tester (continuous impact-abrasion test - CIAT) [3, 7-13] or other specially developed wear testing devices [1, 2, 4-6].

Most of the researches on CIAT devices were conducted with constant relative motion speeds of a sample of about $10 \mathrm{~m} / \mathrm{s}$, so the influence of speed on the wear rate could not be determined $[3,7 \div 13]$. In the researches carried out on special devices, the conclusions were usually identical. The research with low motion speed of $1,35 \mathrm{~m} / \mathrm{s}$ [1], conducted on circular samples, determined that the wear depended on the abrasive hardness and experiment duration. The research with the speed of $60 \mathrm{~m} / \mathrm{s}$ proved that erosion mechanism with hard particles was more expressed at higher speed impact abrasion [2]. Previous researches [14] analysed tillage tools in laboratory and field conditions to determine the influence of motion speed on the wear rate of conventional materials (steels and copper). Significant increase of wear was determined by increasing the motion speed in the range of 0,25 to $7,0 \mathrm{~m} / \mathrm{s}$. This wear was twice as low in laboratory conditions than in field conditions. The influence of motion speed was lower in ductile materials (copper, soft steels), while in harder materials (tempered steel), this influence was significantly higher. The same paper refers to several previous researches into material wear by abrasion with bonded abrasives and abrasion with loose sand, which also confirmed significant influence of motion speed on the amount of wear. All above-mentioned researches indicated that the increase of wear in dependence on speed increase was not linear.

Some studies performed on CIAT devices analyzed the abrasive particle impact angle with the worn surface at a speed of about $10 \mathrm{~m} / \mathrm{s}$ and its influence on the amount of wear $[10,11,13]$. For harder materials, it was determined that the wear at vertical impact $\left(90^{\circ}\right)$ was greater than at an angle of $60^{\circ}[10,11]$, whereas for softer materials (ductile steels), the wear at an angle of $30^{\circ}$ was greater than at a vertical impact, which was associated with the increase of surface micro-cutting by sliding of hard abrasive particles on it. At a vertical impact, such sliding and micro-cutting are significantly smaller, so that the wear of material from the surface is also reduced [13]. This case confirms the importance of abrasion mechanism in the overall wear. Within the researches into the influence of the impact angle on the wear of ductile (untreated) and fragile (tempered) steels, that were carried out on special devices at a speed of $4,76 \mathrm{~m} / \mathrm{s}$, it was determined that the greatest wear of ductile materials occurred at $30^{\circ}$ and then decreased with the increase of the angle up to $90^{\circ}$. For tempered steels, the greatest wear occurred at $45^{\circ}$ and then decreased with the angle increase up to $90^{\circ}$ [4].

The protection of machine parts from the abrasive wear is mostly performed by abrasion resistant coatings that are applied to the base metal by various technological processes, such as high-frequency induction surfacing. These are highly productive processes, easily automated and highly efficient in the serial production. The advantages of induction surfacing are low depth of penetration into the base metal and the possibility of applying thin layers [15]. Due to these advantages, various types of induction procedures can be widely applied. 
Cladding is a process that aims to obtain high-quality properties of expensive surface materials, such as resistance to corrosion and other forms of wear, by combining these properties with the strength and efficiency of inner base material [16]. In general, induction cladding involves electromagnetic, thermal and metallurgical processes, but essentially, it is the procedure of induction heating. Induction cladding is popular because of its production efficiency, fast heating rate, good reproducibility and low energy consumption [17-19]. Moreover, this method enables creation of metallurgical connections that can withstand high impacts, shear and contact stresses [20]. If compared with other cladding technologies (laser, electron beam, plasma cladding), application of induction cladding is easier and cheaper [21].

Within the induction cladding, additional materials that create a coating resistant to abrasion may be in the form of strips, strings, rods, powders, pastes or their mixtures. Powder is the most commonly used additional material, and its composition determines to what extent the coating shall be resistant to abrasion. In most tribology researches, powders for induction cladding are Ni-based alloys with significant content of chromium (Cr) [20, 23$25]$. The abrasion resistance is additionally increased with the content of tungsten carbide (WC) $[22,26]$, titanium carbide (TiC) [26] or multi component mixtures containing boron (B), silicon ( $\mathrm{Si}$ ), cobalt (Co) and similar [28-30]. Obtained coatings exhibit high abrasion resistance, as well as suitability for application in many areas. Although the above-mentioned powders are primarily used in thermal spraying, they are also applicable for induction cladding. When comparing the abrasion resistance of coatings of the

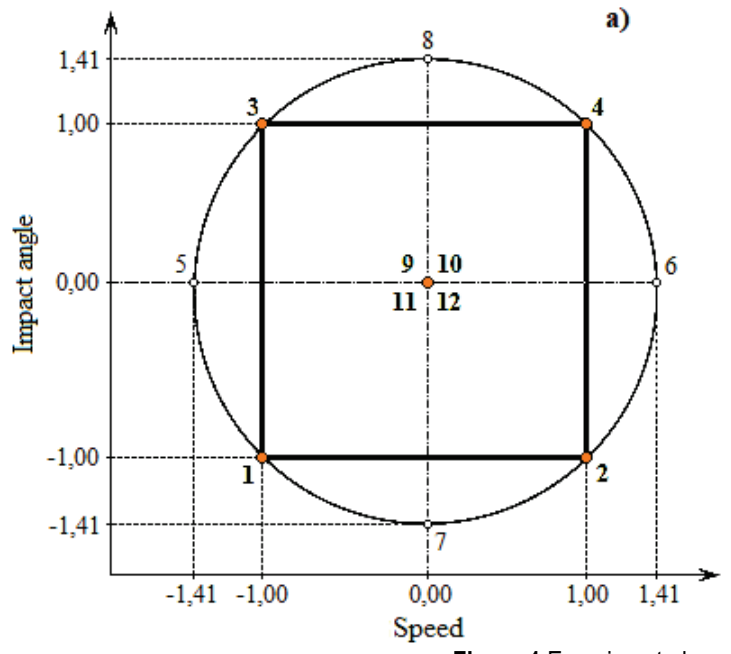

Figure 1 Experiment plan and levels of input parameters

\subsection{Processing of Samples}

Wear testing is performed on samples of dimensions $20 \times 40 \times 5 \mathrm{~mm}$, made of non-alloy carbon steel C45G (substrate) and with chemical composition which is shown in Tab. 1.

Table 1 Chemical composition of the base material $\mathrm{C} 45 \mathrm{G}$

\begin{tabular}{|c|c|c|c|c|c|c|c|c|}
\hline Element & $\mathrm{C}$ & $\mathrm{Si}$ & $\mathrm{Mn}$ & $\mathrm{P}$ & $\mathrm{S}$ & $\mathrm{Cr}$ & $\mathrm{Mo}$ & $\mathrm{Ni}$ \\
\hline Wt. $\%$ & 0,46 & 0,29 & 0,68 & 0,026 & 0,029 & 0,024 & 0,08 & 0,020 \\
\hline
\end{tabular}

same powders obtained by both processes, there is a significant advantage determined for the induction coating. In researches [20], the abrasion resistance was twice as high.

This paper presents the research into the influence of changing motion speed and abrasive particles impact angle on the worn surface of a sample and its influence on the amount of wear of the selected induction-cladded coating. There is also a developed mathematical model that describes the individual and interactive influences of the stated parameters with a high level of statistical significance.

\section{EXPERIMENTAL RESEARCH \\ 2.1 Experiment Plan}

The experiment is focused on the wear testing of induction-cladded samples that move through the abrasive mass at different motion speeds and impact angle of particles with the worn surface of the sample.

In this research, the input variables are the motion speed in range from 1,0 to $3,0 \mathrm{~m} / \mathrm{s}$ and the impact angle of abrasive particle with the worn surface in range from $0^{\circ}$ to $90^{\circ}$. The length of wear path for all samples is $50000 \mathrm{~m}$ $(50 \mathrm{~km})$. Output variable is the loss of mass that occurs because of the sample surface wear.

The experiment is carried out by using the Response Surface Method (RSM) [31]. Since a nonlinear response function of influences by individual factors and by their interaction is expected, there is a central composite design (CCD) applied in the experiment. Figure 1 presents the experiment plan and the levels of input parameters in the coded form (a), and in the actual values (b).

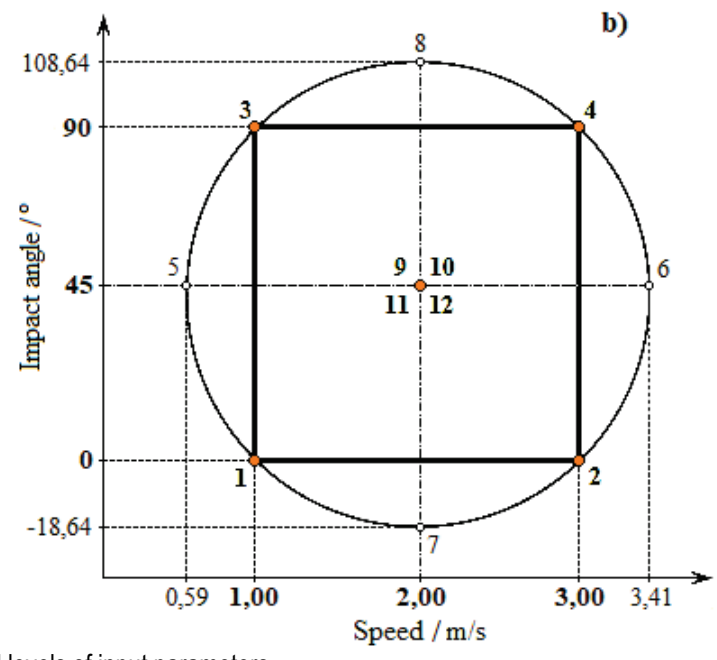

Cladding is performed by using $\mathrm{Ni}-\mathrm{Cr}-\mathrm{Si}-\mathrm{B}-\mathrm{Fe}$ flame spraying powder (UTP HA-6, Böhler Welding). The applied coating enables the hardness of up to $50 \mathrm{HRC}$, and good resistance to corrosion and wear, even at high service temperatures. The powder UTP HA-6 has a granulation of $106 \pm 20 \mu \mathrm{m}$, and its declared chemical composition is overviewed in Tab. 2.

Table 2 Chemical composition of the powder UTP HA-6 [32]

\begin{tabular}{|c|c|c|c|c|c|c|}
\hline Element & $\mathrm{C}$ & $\mathrm{Si}$ & $\mathrm{Cr}$ & $\mathrm{B}$ & $\mathrm{Fe}$ & $\mathrm{Ni}$ \\
\hline wt. $\%$ & 0,45 & 3,8 & 11,0 & 2,3 & 2,9 & rest \\
\hline
\end{tabular}


High frequency induction cladding is applied for coating. The device used for preparation of samples is applied in wear protection of agricultural tillage tools [33]. As shown in Fig. 2, this process comprises the following phases:

- even application of powder on the base material surface in the thickness of approx. $2,5 \mathrm{~mm}$;

- $\quad$ melting of powder and creation of a cladded layer by heating at $1150{ }^{\circ} \mathrm{C}$ and passing through the inductor.

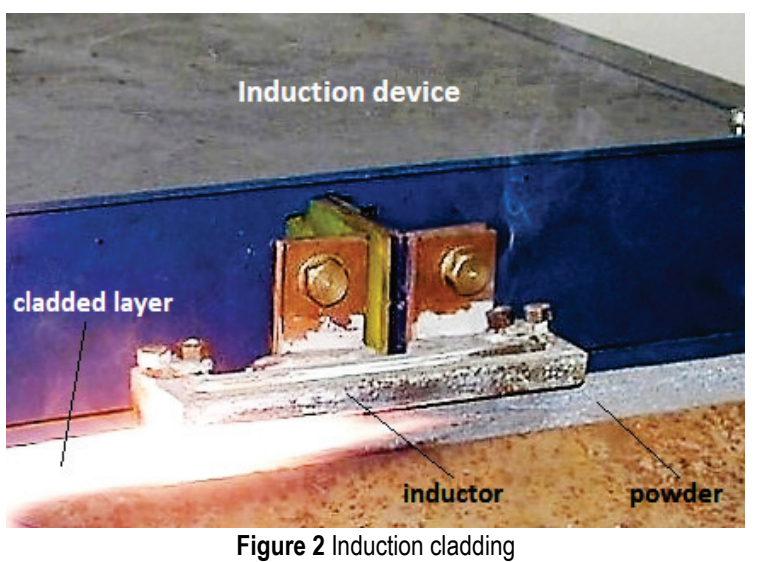

Table 3 Characteristics of high-frequency generator

\begin{tabular}{|l|l|}
\hline Device power & $60 \mathrm{~kW} / 75 \mathrm{kVA}$ (adjustable) \\
\hline Frequency & $66 \mathrm{kHz}$ (adjustable) \\
\hline Power supply & $380 \mathrm{~V}$ \\
\hline Output voltage & $560 \mathrm{~V}$ \\
\hline Coat form & determined by inductor \\
\hline Coat width & up to $200 \mathrm{~mm}$ \\
\hline Coat length & up to $500 \mathrm{~mm}$ \\
\hline Coat thickness & $1-6 \mathrm{~mm}$ (by powder amount) \\
\hline Deposition speed & $2-5 \mathrm{~mm} / \mathrm{s}$ (continuously) \\
\hline Cooling method & autonomous (water) \\
\hline
\end{tabular}

Device for induction heating consists of highfrequency generator, inductor for flat surface heating, the device for attaching parts in the inductor and autonomous installation of water-cooling system. Device characteristics are overviewed in Tab. 3 .

\subsection{Analysis of Material}

Sample microstructure is recorded by inverted metallographic microscope Olympus GX51F-5 with integrated digital camera DP25 and corresponding software for image analysis.

Microanalysis of the cladded layer chemical composition is performed by a scanning electron microscope (SEM) Tescan Vega TS5136LS with energy dispersive X-ray spectroscopy (EDS).

Surface hardness and sample cross-section hardness is measured by Shimadzu Microhardness Tester Type M.

By applying the described technology of induction cladding, the samples are coated by a layer of ca. $1 \mathrm{~mm}$ and with microstructure which is presented in Fig. 3.

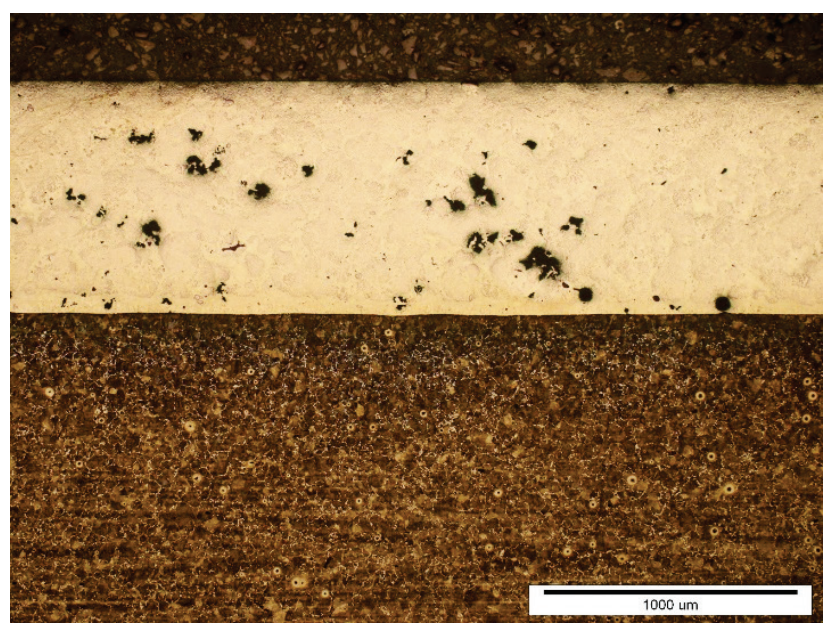

Figure 3 Microstructure of the cladded layer

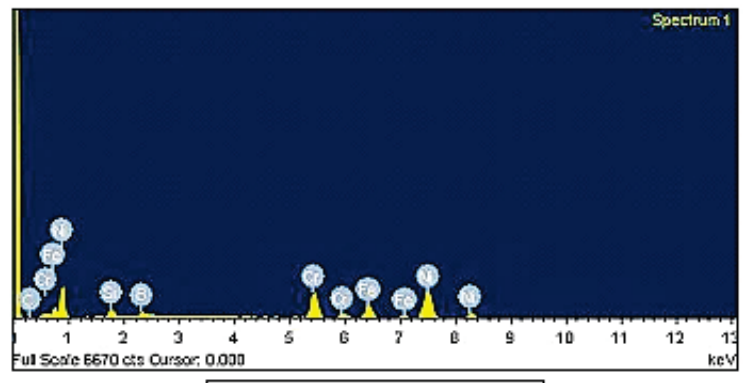

\begin{tabular}{|cc|}
\hline E lement & Weight \% \\
\hline $\mathrm{C} \mathrm{K}$ & 4,17 \\
$\mathrm{Si} \mathrm{K}$ & 3,87 \\
$\mathrm{~B} \mathrm{~K}$ & 1,49 \\
$\mathrm{Cr} \mathrm{K}$ & 12,02 \\
$\mathrm{Fe} \mathrm{K}$ & 15,54 \\
$\mathrm{Ni} \mathrm{K}$ & 62,91 \\
\hline Totals & 100,00 \\
\hline
\end{tabular}

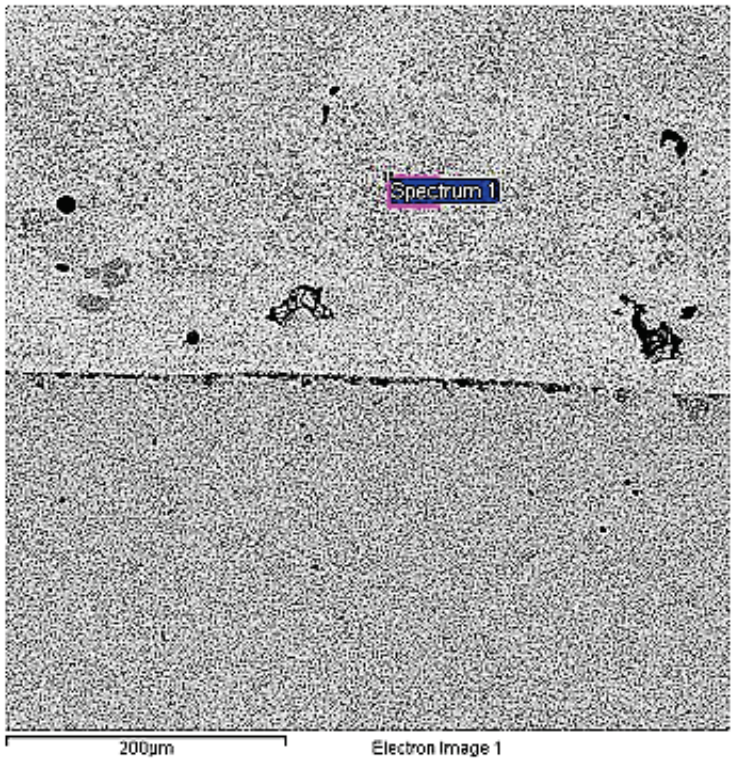

Figure 4 EDS analysis of the cladded layer composition

As of the presented microstructure, it is visible that there is a clear light transitional boundary between the layer and the base material and that there is a very good metallurgical bond. There is a partial porosity within the layer structure, while the layer surface is homogeneous and without porous spots.

The composition of the cladded layer is determined by the EDS analysis, as shown in Fig. 4. 
The obtained layer is measured for its surface hardness of $440 \mathrm{HV}$, and the hardness of cross-section and of base material is presented in Tab. 4 and by Fig. 5 .

Table 4 Hardness at the sample cross-section

\begin{tabular}{|c|c|c|}
\hline Distance $(\mathrm{mm})$ & HV Hardness & HRC Hardness \\
\hline 0,1 & 439 & 44 \\
\hline 0,2 & 435 & 44 \\
\hline 0,3 & 432 & 44 \\
\hline 0,4 & 435 & 44 \\
\hline 0,5 & 439 & 44 \\
\hline 0,6 & 432 & 44 \\
\hline 0,7 & 439 & 44 \\
\hline 0,8 & 435 & 44 \\
\hline 0,9 & 439 & 44 \\
\hline 1,0 & 432 & 44 \\
\hline 1,1 & 413 & 42 \\
\hline 1,2 & 404 & 41 \\
\hline 1,3 & 401 & 41 \\
\hline 1,4 & 373 & 38 \\
\hline 1,5 & 373 & 38 \\
\hline 1,6 & 315 & 32 \\
\hline 1,8 & 254 & 23 \\
\hline 2,0 & 254 & 23 \\
\hline 2,2 & 257 & 23 \\
\hline 2,4 & 249 & 22 \\
\hline 2,6 & 246 & 22 \\
\hline 2,8 & 255 & 23 \\
\hline 3,0 & 254 & 23 \\
\hline 3,5 & 255 & 23 \\
\hline 4,0 & 255 & 23 \\
\hline 5,0 & 246 & 22 \\
\hline
\end{tabular}

a)

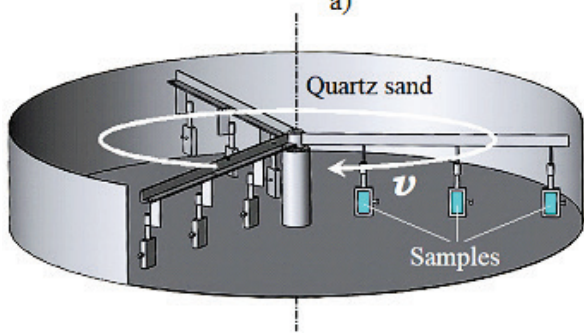

Figure 6 Shema of the device used in wear testing (a), and placing of the sample into the holder (b)

During the experiment performance, there is just one sample surface in dimension of $20 \times 40 \mathrm{~mm}$ exposed to wear, which is enabled by placing the sample in the holder that protects other sample surfaces from wear, as presented at Fig. 6 b.

Wear testing is performed in the mass of free abrasive particles in the standard quartz sand Ottawa AFS 50/70, of rounded grain size $212 \div 300 \mu \mathrm{m}$, the morphology of which is shown in Fig. 7.

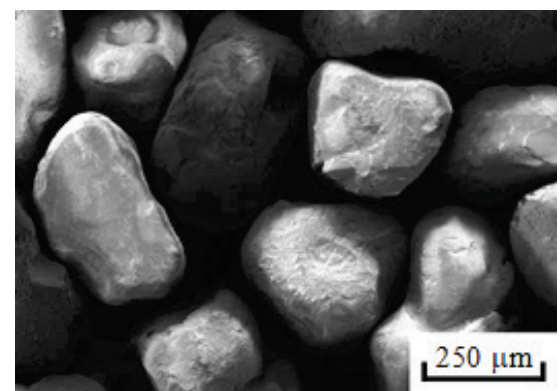

Figure 7 Morphology of quartz sand Ottawa AFS 57/70 (SEM image)

Masses of samples before and after wear testing are measured by analytical scale Mettler B5C 1000, with
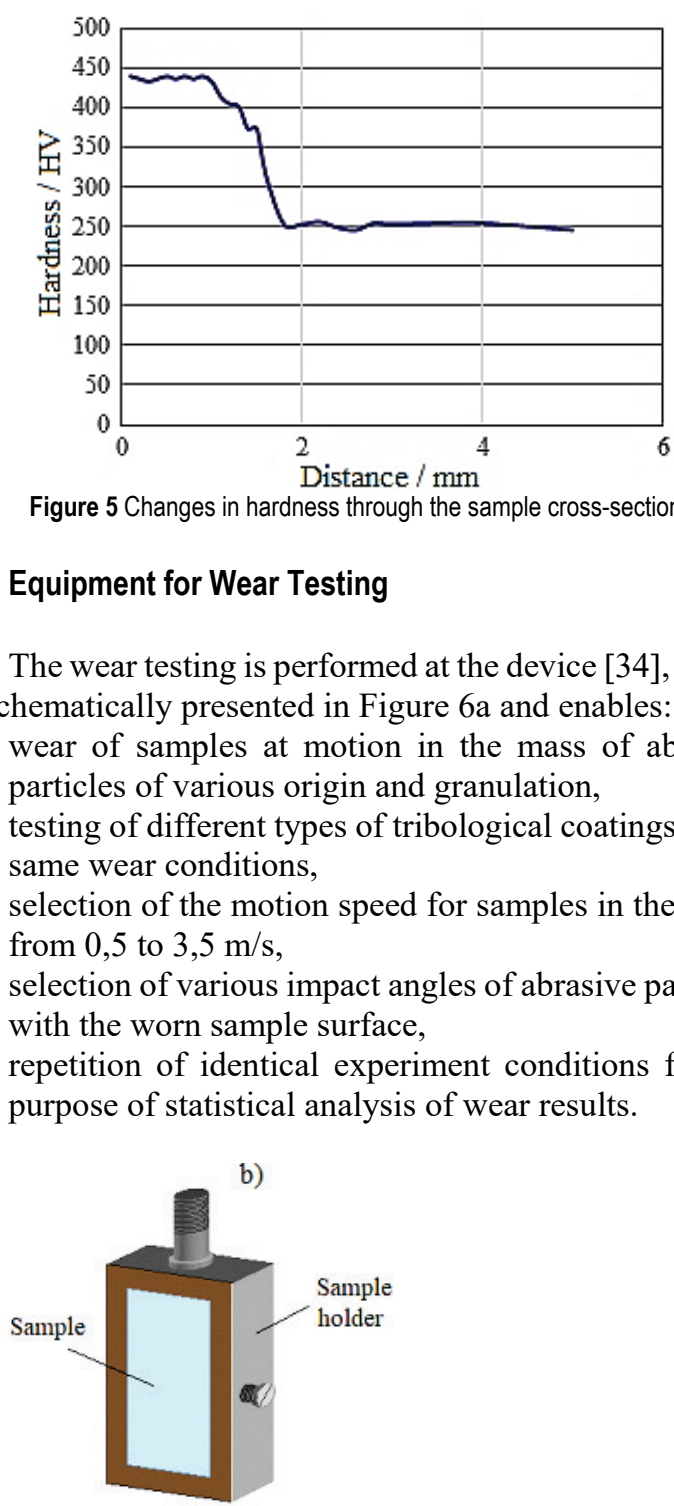

Figure 5 Changes in hardness through the sample cross-section

\subsection{Equipment for Wear Testing}

The wear testing is performed at the device [34], which is schematically presented in Figure 6a and enables:

- wear of samples at motion in the mass of abrasive particles of various origin and granulation,

- testing of different types of tribological coatings in the same wear conditions,

- $\quad$ selection of the motion speed for samples in the range from 0,5 to $3,5 \mathrm{~m} / \mathrm{s}$,

- $\quad$ selection of various impact angles of abrasive particles with the worn sample surface,

- repetition of identical experiment conditions for the purpose of statistical analysis of wear results.

precision of $10^{-4} \mathrm{~g}$. Differences in measured masses of samples are the loss mass because of wear.

\section{RESULTS AND DISCUSSION}

Statistical data processing is carried out by using the licensed software Design-Expert (v. 6.0.8, Stat-Ease, Inc., Minneapolis, 2002). The results of the performed wear testing are shown in Tab. 5, by applying the randomization principle in the experiment sequence.

Table 5 Results of wear testing
\begin{tabular}{|c|c|c|c|c|}
\hline Std & Run & $\begin{array}{c}\text { Factor 1 } \\
\text { A: Speed } / \mathrm{m} / \mathrm{s}\end{array}$ & $\begin{array}{c}\text { Factor 2 } \\
\text { B: Impact angle } /{ }^{\circ}\end{array}$ & $\begin{array}{c}\text { Response: } \\
\text { Mass loss } / 10^{-4} \mathrm{~g}\end{array}$ \\
\hline 8 & 1 & 2,00 & 108,64 & 13,00 \\
\hline 9 & 2 & 2,00 & 45,00 & 73,00 \\
\hline 6 & 3 & 3,41 & 45,00 & 161,00 \\
\hline 7 & 4 & 2,00 & $-18,64$ & 42,00 \\
\hline 10 & 5 & 2,00 & 45,00 & 73,00 \\
\hline 4 & 6 & 3,00 & 90,00 & 71,00 \\
\hline 12 & 7 & 2,00 & 45,00 & 76,00 \\
\hline 11 & 8 & 2,00 & 45,00 & 81,00 \\
\hline 5 & 9 & 0,59 & 45,00 & 72,00 \\
\hline 3 & 10 & 1,00 & 90,00 & 47,00 \\
\hline 2 & 11 & 3,00 & 0,00 & 131,00 \\
\hline 1 & 12 & 1,00 & 0,00 & 63,00 \\
\hline
\end{tabular}


The response surface model is selected by using the sum of squares method, as presented in Tab. 6 .

For the experiment, there is the suggested model of quadratic polynomial that has the highest $F$-value $(57,81)$.
The significance of the suggested model is supported by the value of Prob $>F$, which is lower than $0,05 \%$.

Table 6 Selection of response surface mode

\begin{tabular}{|c|c|c|c|c|c|c|}
\hline \multicolumn{4}{|c|}{ Sequential Model Sum of Squares } & \multirow[b]{2}{*}{$F$-value } & \multirow[b]{2}{*}{ Prob $>F$} & \\
\hline Source & Sum of Squares & $D F$ & Mean Square & & & \\
\hline Mean & 67950,75 & 1 & 67950,75 & & & \\
\hline Linear & 7644,63 & 2 & 3822,31 & 3,90 & 0,0602 & \\
\hline $2 \mathrm{FI}$ & 484,0 & 1 & 484,0 & 0,46 & 0,5147 & \\
\hline Quadratic & 7922,50 & 2 & 3961,25 & 57,81 & 0,0001 & Suggested \\
\hline Cubic & 296,37 & 2 & 148,19 & 5,17 & 0,0779 & \\
\hline Residual & 114,75 & 4 & 28,69 & & & \\
\hline Total & 84413,0 & 12 & 7034,42 & & & \\
\hline
\end{tabular}

Testing of the significance of the model and of the experiment variables is performed by analysis of variance (ANOVA), as it is overviewed in Tab. 7.

The model $F$-value of 46,85 points out its significance. The Prob $>F$ value indicates that there is only $0,01 \%$ probability that such high $F$-value occurred because of noise.

Lack of Fit in the amount of 8,62 indicates the existence of noise, yet the value of Prob $>$ F shows that this affects the model by only $5,51 \%$, which is not significant.
The value of Prob $>F$ for the polynomial members that are lower than 0,0500 indicates their significance in the wear model.

From the analysis of variance is visible that all polynomial members (A, B, A2, B2, AB) have the Prob > $F$ value lower than 0.0500 . This means that both variables of the experiment have significant influence on the wear, both in individual form and in mutual interaction. By considering their $F$-values, it can be concluded that the motion speed has the most important influence, and that the interaction of variables has the least important influence.

Table 7 Analysis of variance for the suggested response surface model

\begin{tabular}{|c|c|c|c|c|c|c|}
\hline \multicolumn{7}{|c|}{ ANOVA for Response Surface Quadratic Model } \\
\hline Source & Sum of Squares & $D F$ & Mean Square & $F$-value & Prob $>F$ & \\
\hline Model & 16051,13 & 5 & 3210,23 & 46,85 & $<0,0001$ & Significant \\
\hline A-speed & 5933,15 & 1 & 5933,15 & 86,59 & $<0,0001$ & \\
\hline $\mathrm{B}$ - impact angle & 1711,48 & 1 & 1711,48 & 24,98 & 0,0025 & \\
\hline $\mathrm{A} 2$ & 3062,50 & 1 & 3062,50 & 44,69 & 0,0005 & \\
\hline B2 & 3276,10 & 1 & 3276,10 & 47,81 & 0,0005 & \\
\hline $\mathrm{AB}$ & 484,0 & 1 & 484,0 & 7,06 & 0,0376 & \\
\hline Residual & 411,12 & 6 & 68,52 & & & \\
\hline Lack of Fit & 368,37 & 3 & 122,79 & 8,62 & 0,0551 & Not significant \\
\hline Pure Error & 42,75 & 3 & 14,25 & & & \\
\hline Cor Total & 16462,25 & 11 & & & & \\
\hline
\end{tabular}

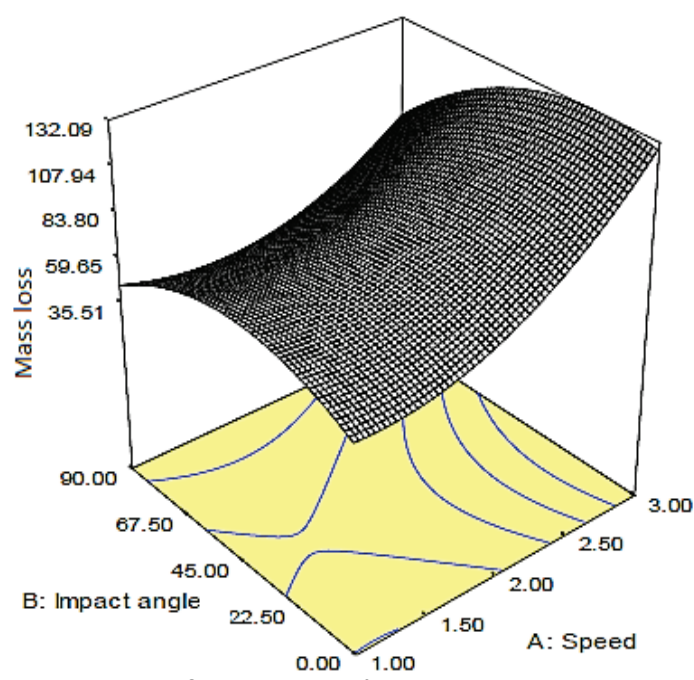

Figure 8 Spatial diagram of the mathematical model

There is a mathematical model developed in the coded form for the suggested response surface model:

$$
\begin{aligned}
\dot{Y}= & 75,75+27,23 \cdot A-14,63 \cdot B+21,88 \cdot A^{2}- \\
& -222,62 \cdot B^{2}-11,00 \cdot A B
\end{aligned}
$$

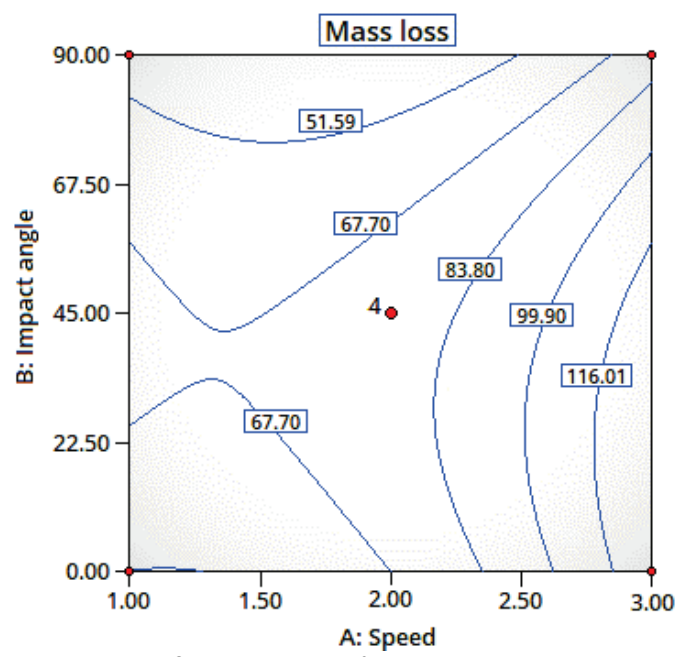

Figure 9 Contour diagram of the mathematical model

By decoding the model in the coded form, a final mathematical model of wear with actual values of the experiment input variables is obtained:

$$
\begin{aligned}
\Delta m= & 78,78527-49,26687 \cdot v+1,16941 \cdot \alpha+ \\
& +21,87500 \cdot v^{2}-0,011173 \cdot \alpha^{2}-0,24444 \cdot v \cdot \alpha
\end{aligned}
$$


Developed mathematical model of wear is presented by diagrams of the response surface:

- $\quad$ spatial diagram, shown in Fig. 8,

- contour diagram, shown in Fig. 9,

- curves of the interactive influence of the input variables, shown in Fig. 10.

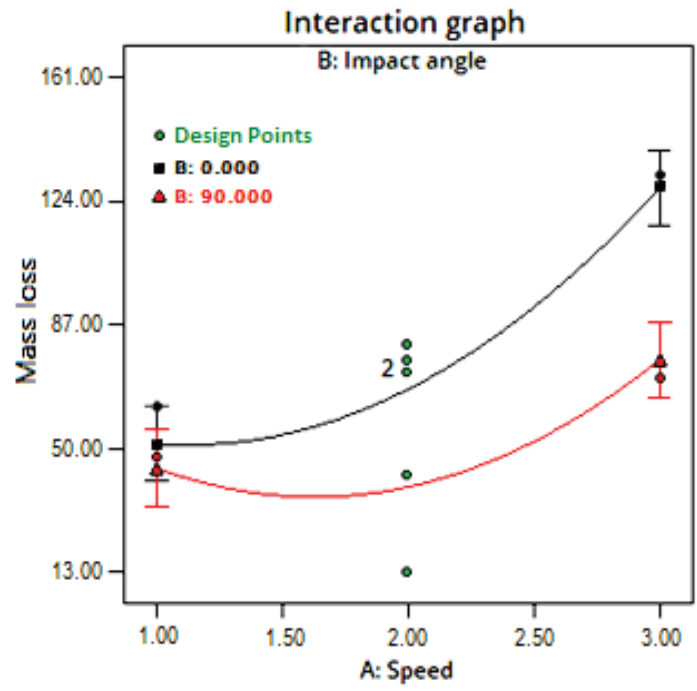

Figure 10 Curves of the interactive influence of the input variables

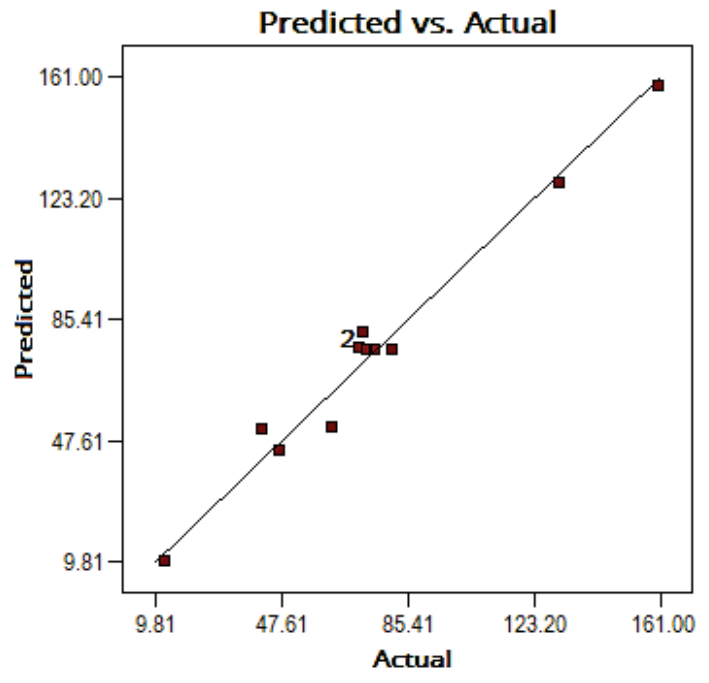

Figure 11 Comparison of actual and predicted data

Comparison of the actually measured data obtained in the wear experiment and the predicted data obtained in the suggested model of quadratic polynomial determines their dispersion, i.e. their mutual deviation. The diagram in Fig. 11 shows slight dispersion of the data, which confirms the applicability of the suggested wear model.

\section{CONCLUSION}

The research is carried out to determine the wear of coated samples, obtained by induction cladding with $\mathrm{Ni}$ $\mathrm{Cr}-\mathrm{Si}-\mathrm{B}-\mathrm{Fe}$ flame spraying powder. Samples are tested in conditions of motion through the mass of free abrasive particles. The mentioned coating proved satisfactory resistance and applicability in technical systems that are exposed to the examined cases of wear.

Induction cladding is also proved to be applicable in practice, since it can provide a hard layer of appropriate surface hardness, with good metallurgical bond with the base material and with low porosity within the layer that does not reduce the abrasion resistance of the entire coating.

Statistical analysis of experiment results lead to the creation of a mathematical model of wear in the form of quadratic polynomial that describes the influences of the input variables, both in individual and in the interactive form.

Motion speed had the greatest influence on wear of the cladded coating, as the wear rate of coating increased along with the increase of speed at all impact angles.

Impact angle of abrasive particles and worn surface affects the wear of coating, so that at a speed of $1 \mathrm{~m} / \mathrm{s}$ the wear increases along with the angle increase from $0^{\circ}$ to $45^{\circ}$, and then it decreases with the further increase of the angle up to $90^{\circ}$. At a speed of $2 \mathrm{~m} / \mathrm{s}$, the wear increases along with the increase of the angle from $0^{\circ}$ to $30^{\circ}$, and then it decreases with the further angle increase up to $90^{\circ}$. At a speed of $3 \mathrm{~m} / \mathrm{s}$, the wear increases by the angle increase from $0^{\circ}$ to $20^{\circ}$, and then it decreases with the further angle increase up to $90^{\circ}$.

Motion speed and impact angle have significant interactive influence on the wear of coating.

Predicted and actual values are satisfactorily close, which confirms that the developed quadratic model of wear can be efficiently used in predicting the wear of the cladded coating.

\section{REFERENCES}

[1] Sari, N. Y. \& Yilmaz, M. (2006). Investigation of abrasive + erosive wear behaviour of surface hardening methods applied to AISI 1050 steel. Materials and Design, 27, 470478. https://doi.org/10.1016/j.matdes.2004.11.020

[2] Tarbe, R. \& Kulu, P. (2008). Impact wear tester for the study of abrasive erosion and milling processes. $6^{\text {th }}$ International $D A A A M$ Baltic Conference "Industrial Engineering", Tallinn, Estonia.

[3] Franek, F., Badisch, E., \& Kirchgaßner, M. (2009). Advanced Methods for Characterisation of Abrasion/ Erosion Resistance of Wear Protection Materials. FME Transactions, 37(2), 61-70.

[4] Kosa, E. \& Göksenli, A. (2015). Effect of Impact Angle on Erosive Abrasive Wear of Ductile and Brittle Materials. World Academy of Science, Engineering and Technology, International Journal of Mechanical and Mechatronics Engineering, 9(9), 1638-1642.

[5] Vuorinen, E., Ojala, N., Heino, V., Rau, C., \& Gahm, C. (2016). Erosive and abrasive wear performance of carbide free bainitic steels - comparison of field and laboratory experiments. Tribology International, 98, 108-115. https://doi.org/10.1016/j.triboint.2016.02.015

[6] Valtonen, K., Keltamäki, K., \& Kuokkala, V.-T. (2018). High-stress abrasion of wear resistant steels in the cutting edges of loader buckets. Tribology International, 119, 707720. https://doi.org/10.1016/j.triboint.2017.12.013

[7] Badisch, E., Kirchgaßner, M., Polak, R., \& Franek, F. (2008). The comparison of wear properties of different Febased hardfacing alloys in four kinds of testing methods. Tribotest, 14, 225-233. https://doi.org/10.1002/tt.61

[8] Badisch E., Ilo, S., \& Polak, R. (2009). Multivariable Modeling of Impact-Abrasion Wear Rates in Metal MatrixCarbide Composite Materials. Tribology Letters, 36, 55-62. https://doi.org/10.1007/s11249-009-9458-y 
[9] Katsich, C. \& Badisch, E. (2011). Effect of carbide degradation in a Ni-based hardfacing under abrasive and combined impact/abrasive conditions. Surface and Coatings Technology, 206(6), 1062-1068. https://doi.org/10.1016/j.surfcoat.2011.07.064

[10] Ratia, V., Valtonen, K., Kuokkala, V.-T. (2013). Impactabrasion wear of wear resistant steels at perpendicular and tilted angles. Proceedings of the Institution of Mechanical Engineers Part J: Journal of Engineering Tribology, 227, 868-877. https://doi.org./10.1177/1350650113487831

[11] Ratia, V., Miettunen, I., \& Kuokkala, V.-T. (2013). Surface deformation of steels in impact-abrasion: the effect of sample angle and test duration. Wear, 301, 94-101. https://doi.org./10.1016/j.wear.2013.01.006

[12] Antonov, M., Veinthal, R., Yung, D-L., Katušin, D., \& Hussainova, I. (2015). Mapping of impact-abrasive wear performance of WC-Co cemented carbides. Wear, 332-333, 971-978. https://doi.org/10.1016/j.wear.2015.02.031

[13] Ratia, V., Valtonen, K., Kemppainen A., \& Kuokkala V.-T. (2016). The Role of Edge-Concentrated Wear in ImpactAbrasion Testing. Tribology Online, 11(2), 410-416. https://doi.org/10.2474/trol.11.410

[14] Moore, M. A. \& McLees, V. A. (1980). Effect of speed on wear of steels and a copper by bonded abrasive and soils. Journal of Agricultural Engineering Research, 25, 37-45. https://doi.org/10.1016/0021-8634(80)90045-1

[15] Poulka, Ch. V., Gavrilyuk V. Ya., \& Senchishin, V. S. (2014). Improving induction surfacing equipment and technology. Welding International, 28(4), 320-323. https://doi.org/10.1080/09507116.2013.796681

[16] Mateša, B., Samardžić, I., \& Dunđer, M. (2014). Heat treatment influence on clad dissimilar joints weakness. Tehnički vjesnik, 21(5), 1035-1040.

[17] Yang L. \& Li, G. (2011). Microstructure and Property of Wear-resistant Coating Layer by High-frequency Induction Cladding on Mild Steel Surface. Advanced Materials Research, 239-242, 773-776. https://doi.org/10.4028/www.scientific.net/AMR.239-242.773

[18] Li, C-k., Liu, Y-c, Shi, Y-j., Yi, P., Xie, J-h., Ma, X-1., \& Cui, L-f. (2016). Modeling of High-Frequency Induction Heating Surface Cladding Process: Numerical Simulation, Experimental Measurement and Validation. Proceedings of the $6^{\text {th }}$ International Asia Conference on Industrial Engineering and Management Innovation. Atlantis Press, Paris, 747-759. https://doi.org/10.2991/978-94-6239-148-2_74

[19] Pulka, Ch. V., Shably, O. N., Baranovsky, V. N., Senchishin, V. S., \& Gavrilyuk, V. Ya. (2015). Ways of updating the technology of induction surfacing of thin steel discs. The Paton Welding Journal, 5-6, 59-62. https://doi.org/10.15407/tpwj2015.06.14

[20] Zhu, J. F., Xiao, W. F., Liu, G., \& Wang, S. L. (2013). The Property Comparison of Coating Prepared by OxygenAcetylene Spray Welding Technology and High-Frequency Induction Remelting Technology. Advanced Materials Research, 652-654, 1805-1809. https://doi.org/10.4028/www.scientific.net/AMR.652-654.1805

[21] Wang, Z. \& Wang, Y. (2007). Microstructure and Properties of In-Situ Synthesis of TiC Particle Reinforced Composite Coating by Induction Cladding. Key Engineering Materials, 336-338, 1725-1727. https://doi.org/10.4028/www.scientific.net/KEM.336-338.1725

[22] Xu, M., Zhu, S., \& Ding, H. (2015). Electrical contact strengthening of induction-clad $\mathrm{Ni}-40 \%$ WC composite coatings on $40 \mathrm{Cr}$ substrates. Surface \& Coatings Technology, 279, 32-38. https:// doi.org/10.1016/j.surfcoat.2015.08.029

[23] Yu, F., Liu, J. W., Ren, L. D., \& Wang, D. Q. (2011). Study on Technique of Induction Cladding Alloy Layer in Steel Tube Outer Wall and Property of Alloy Layer. Advanced Materials Research, 295-297, 203-207.
https://doi.org/10.4028/www.scientific.net/AMR.295-297.203

[24] Liu, J. W. \& Zhang, F. X. (2015). Research on Induction Cladding Alloy Layer on the Surface of Steel Parts and its Performance. Advanced Materials Research, 1095, 620-625. https://doi.org/10.4028/www.scientific.net/AMR.1095.62

[25] Zhu, F. D., Zhu, B. J., \& Liu, J. (2014). Research on the NiCr Alloy Coatings on the Hydraulic Prop by High-Frequency Induction Cladding. Advanced Materials Research, 936, 1878-1881. https://doi.org/10.4028/www.scientific.net/AMR.936.1878

[26] Wei, X., Wang, G. K., Chang, Y. F., \& Liu, C. (2011). Study on WC-Ni60 Complex Coating by High Frequency Induction Cladding. Materials Science Forum, 675-677, pp. 1299-1302. https://doi.org/10.4028/www.scientific.net/MSF.675-677.1299

[27] Yu, H. L., Zhang, W., Wang, H. M., Ji, X. C., Song, Z. Y., $\mathrm{Li}, \mathrm{X}$. Y., \& Xu, B. S. (2017). In-situ synthesis of TiC/Ti composite coating by high frequency induction cladding. Journal of Alloys and Compounds, 701, 244-255. https://doi.org/10.1016/j.jallcom.2017.01.084

[28] Lu, S.-P., Kwon, O. Y., \& Guo, Y. (2003). Wear behavior of brazed WC/NiCrBSi(Co) composite coatings. Wear, 254(5), 421-428. https://doi.org/10.1016/S043-1648(03)00132-7

[29] Horvat, Z., Marušić, V., Samardžić, I., \& Opačak O. (2018). Influence of ploughshare surface layers on ploughing efficiency. Metalurgija, 57(1-2), 125-127.

[30] Chen, X., Qin, X., Gao, K., Zhu, Z., \& Huang, F. (2018). Microstructural Evolution of NiCrBSi Coatings Fabricated by Stationary Local Induction Cladding. Journal of Materials Engineering and Performance, 27, 24462456. https://doi.org/10.1007/s11665-018-3344-4

[31] Myers, R. H. \& Montgomery, D. C. (2002). Response surface methodology. John Wiley \& Sons, New York.

[32] (2012). UTP Schweissmaterial. UTP Welding Guide. Böhler Schweisstechnik Deutschland GmbH, Bad Krozingen, Deutschland.

[33] Banaj, Đ., Duvnjak, V., Tadić, V., Kanisek, J., \& Turkalj, D. (2008). Tehničko-tehnološki aspekti primjene novih oblika lemeša pluga. Poljoprivreda, 14(1), 41-46.

[34] Heffer, G. (2002). Trošenje triboloških prevlaka pri gibanju u masi slobodnih abrazijskih čestica. Doktorska disertacija, Fakultet strojarstva i brodogradnje, Zagreb.

\section{Contact information}

Goran HEFFER, PhD, Full Professor

Faculty of Agrobiotechnical Sciences Osijek, Josip Juraj Strossmayer University of Osijek, Vladimira Preloga 1, 31000 Osijek, Croatia E-mail: goran.heffer@pfos.hr

Ivan SAMARDŽıć, PhD, Full Professor Mechanical Engineering Faculty in Slavonski Brod, Josip Juraj Strossmayer University of Osijek, Trg Ivane Brlić-Mažuranić 2, 35000 Slavonski Brod, Croatia E-mail: isamar@sfsb.hr

\section{Zdravko SCHAUPERL, PhD, Full Professor \\ University of Zagreb, \\ Faculty of Mechanical Engineering and Naval Architecture Ivana Lučića 5, 10000 Zagreb, Croatia \\ E-mail: zdravko.schauperl@fsb.hr}

Ivan VIDAKOVIĆ, MEng, Assistant

Faculty of Agrobiotechnical Sciences Osijek, Josip Juraj Strossmayer University of Osiiek Vladimira Preloga 1, 31000 Osijek, Croatia E-mail: ivan.vidakovic@pfos.hr 